\title{
Adaptation, optimality and functional explanation: Two serious problems
}

\author{
Frederick J. Newmeyer
}

Department of Linguistics, University of Washington, Seattle, WA 98195-4340 USA

fjn@u.washington.edu

I am a formal linguist who has long taken the position that there is no fundamental incompatibility between the program of constructing autonomous models of grammar and that of advancing functional explanations for why grammars have the properties that they have (see, for example, Newmeyer 1991, 1998). I therefore read the target article with great pleasure. In broad outline, Haspelmath puts forward a position quite congenial to mine. Formal principles ('Stay', 'Telegraph', 'Recoverability', and so on) interact to characterize the well-formed sentences of the language. These principles are rooted historically in what Haspelmath calls 'user optimality'. In short, 'grammatical constraints are ultimately based on the constraints on language users' (\$3). Haspelmath chooses the framework of Optimality Theory (OT) as his grammatical model for two reasons. First, because $O T$ constraints seem to be rooted functionally in a more transparent way than are constraints provided by other frameworks. Second, because the OT mechanism of ranked (and rerankable) constraints is well suited to capturing typological variation.

My feeling, however, is that Haspelmath overestimates the ability of OT to serve the purposes he wishes to attribute to it. After defending this point, I will raise a more general problem pertaining to functional explanation that arises if one adopts the assumptions of the target article.

OT analyses, particular in the realm of syntax, have, in general, been rather circumscribed in their domain of application. Typically, they focus on some little corner of the syntax, such as clitic order, auxiliary inversion, and so on. The machinery intrinsic to the OT approach works beautifully in such situations. But grammars are tightly integrated wholes, so decisions about how one process should be handled are likely to have repercussions for another, seemingly unrelated, process. As I will now argue, this fact leads ultimately to a much greater disparity between grammatical principles and their functional roots than Haspelmath believes to be the case.

Let's posit two hypothetical OT constraints for English, FORM-MEANING ALIGNMENT (FMA) and HEAVY-LAST: 
FMA: Syntactic constituents reflect semantic units.

HEAVY-LAST: Heavy constituents follow light constituents.

FMA can be illustrated by the fact that, in every formal account, adjectives are generated under the same phrasal node as the noun that they modify. HEAVYLAST can be illustrated by the fact that within the verb phrase, sentential complements are positioned after phrasal complements. The functional roots of these constraints are so obvious that no discussion is necessary.

Now, then, which constraint is ranked higher for English, FMA or HEAVY. LAST? Well, it depends. In some cases, we have identical grammatical elements in variant orders with no meaning difference, each option corresponding to a different ranking of the two constraints. For example, both of the following are grammatical English sentences:

a. A man who was wearing a silly-looking red hat dropped by today. b. A man dropped by today who was wearing a silly-looking red hat.

Sentence (1 a) reflects a ranking of FMA over HEAVY-LAST; sentence (1 b) the reverse ranking. In some cases, however, only a higher ranking of FMA is possible. Simple adjective phrases cannot be extraposed from the nouns that they modify, no matter how heavy they are:

(2) a. An extremely peculiar-looking man dropped by today.

b. *A man dropped by today extremely peculiar-looking.

And in other cases, HEAVY-LAST seems to be ranked over FMA. When comparatives are used attributively, the adjective is separated from its complement by the head noun, despite the fact that together they serve to modify semantically that head noun $(3 a-b)$. Their structural unity can be obtained only in a manner that is consistent with HEAVY-LAST (3c):
a. That's a more boring book than any I have ever read.
b. *That's a more boring than I have ever read book.
c. That's a book more boring than any I have ever read.

What is the solution to this ranking paradox? Only, I would say, to abandon FMA and HEAVY-LAST as constraints of English grammar. Rather, what we need are something much more like the 'parochial' rules, principles, and constraints of standard models of generative grammar that interact to yield the grammatical sentences of the language. There is a serious problem with such a solution, however, from the point of view of the target article. Consider the relationship between detailed grammatical statements, such as those, for example, that position the constituents of NP and their functional motivations. 
This relationship tends to be vastly more indirect than is the case for general constraints such as FMA and HEAVY-LAST. In other words, we are left with the sort of view advocated in Newmeyer (1998), in which, in a global sense, grammars reflect external forces, but without each language-internal grammatical statement being tied to a particular functional motivation (see, for example, the diagram in Newmeyer 1998: 163).

I will close by discussing briefly a consequence of the conclusions of the target article that appear to have serious implications for the program of functional linguistics. Let us suppose that Haspelmath is correct to endorse Croft's idea that the propagation of linguistics features [is] exclusively [due] to 'social selection', [rather than] 'functional selection' (\$5). Given that social selection and functional selection are independent variables, it follows that in about $50 \%$ of the cases in which two variant forms 'compete', the more functionally motivated variant will be propagated. Now consider innovations in speech. Haspelmath suggests that that they are frequently functionally motivated by user-based criteria and I am sure that he is right. But it must be acknowledged that they are often not functionally motivated. Haspelmath himself (footnote 10) describes grammaticalization changes, which are rampant in language history, as 'counter-adaptive'. Social selection must also play a major role in innovations, as when speakers adopt a form or construction from a more prestigious dialect or language with which they are in contact. Many such borrowings have dysfunctional consequences, viz. the cumbersome rule for word stress in English that followed the entry into that language of hundreds of Old French words following the Norman Conquest. And many other types of innovations appear to be utterly nonfunctional as well. Consider, for example, the unconditioned fronting of [u] to [ū] in French and a parallel development in Scottish English. So let's say (arbitrarily) that $60 \%$ of all innovations are functionally adaptive from the point of the language user. Multiplying the $60 \%$ of user-friendly innovations by the $50 \%$ of user-friendly propagations yields the conclusion that only about $30 \%$ of language changes are ultimately user-based.

Could that be right? It seems to contradict the conclusions of decades of functionalist theorizing (not to mention the premise of the target article) that grammars are, a certain amount of arbitrariness aside, 'designed' for the user. And if it is right, then it would appear that there are important foundational issues in functional linguistics that need to be addressed. If fewer than a third of language changes are functionally motivated, then one would be forced to conclude, along with William Labov (1994) that there has been an "overestimation of functionalism'. If functionalism has not been overestimated, then there is a flaw somewhere in the reasoning that led to my pessimistic conclusion. Haspelmath is capable of pinpointing the flaw, if anybody is. 